\title{
Effect of Lactobacillus plantarum and Leuconostoc mesenteroides starter cultures in lower salt concentration fermentation on the sauerkraut quality
}

\author{
1,* Zubaidah, E., ${ }^{1}$ Susanti, I., ${ }^{1}$ Yuwono, S.S., ${ }^{2}$ Rahayu, A.P., ${ }^{3}$ Srianta, I. and ${ }^{4}$ Blanc, P.J. \\ ${ }^{1}$ Department of Food Science and Technology, Faculty of Agricultural Technology, Brawijaya University, \\ Jalan Veteran Malang, Indonesia 65145 \\ ${ }^{2}$ Department of Agronomy, Faculty of Agriculture, Brawijaya University, Jalan Veteran Malang, Indonesia \\ 65145 \\ ${ }^{3}$ Department of Food Technology, Faculty of Agricultural Technology, Widya Mandala Catholic \\ University Surabaya, Jalan Dinoyo 42-44, Surabaya, Indonesia 60265 \\ ${ }^{4}$ Université de Toulouse, INSA, LISBP, CNRS, UMR5504, INRA, UMR792, Ingénierie des Systèmes \\ Biologiques et des Procédés, 135 Avenue de Rangueil, F-31077 Toulouse, France
}

\begin{abstract}
Article history:
Received: 16 January 2020

Received in revised form: 1

February 2020

Accepted: 3 February 2020

Available Online: 10 March 2020
\end{abstract}

Keywords:

Antioxidant,

Lactobacillus plantarum,

Leuconostoc mesenteroides,

Sauerkraut

DOI:

https://doi.org/10.26656/fr.2017.4(4).029

\begin{abstract}
This research was aimed to study the effect of Lactobacillus plantarum and Leuconostoc mesenteroides starter cultures application in lower salt concentration fermentation on sauerkraut quality. Fresh cut cabbage was fermented with different starter cultures $(L$. plantarum, $L$. mesenteroides or the combination) at different lower salt concentration $(0.5 \%$ or $1 \%)$ at $28^{\circ} \mathrm{C}$ for 5 days. The obtained sauerkrauts were subjected to evaluation of the quality i.e. total lactic acid bacteria, $\mathrm{pH}$, total acidity, total phenolic content and DPPH scavenging activity analysis. The sulforaphane content analysis was performed by using LC-MS. The starter cultures increased total lactic acid bacteria, total acidity and decreased pH. L. mesenteroides resulted in the highest total phenolic content and the lowest $\mathrm{IC}_{50}$ value. Sauerkraut with the addition of $L$. mesenteroides contains sulforaphane higher $848.65 \mathrm{ng} / \mathrm{g}$ than that of control $776.47 \mathrm{ng} / \mathrm{g}$. The results analysis of LC-MS also detected another compound, namely 2-phenethyl isothiocyanate, an antimicrobial compound. The sauerkraut is potential in functional food development with antiproliferative, antiinflammatory, antioxidant, and anti-cancer activities.
\end{abstract}

\section{Introduction}

Lactic acid fermentation is expected to become an important role in the development of functional fermented vegetables. Sauerkraut, fermented cucumbers and kimchi are the most studied lactic acid fermented vegetables mainly due to their commercial importance (Swain et al., 2014). Sauerkraut, means sour cabbage, is a fermentation product of cabbage through spontaneous lactic acid bacteria fermentation. In the fermentation, fresh cabbage is shredded and mixed with $2-2.5 \%$ salt to pull out water and nutrients from the cabbage, and the juice will become a substrate for the lactic acid bacteria growth (Johanningsmeier et al., 2007). Several lactic acid bacteria play an important role in the fermentation process i.e. L. mesenteroides, Lactobacillus cucumeris, L. plantarum and Lactobacillus pentoacetius (Lu et al., 2003; Plengvidhya et al., 2007; Swain et al., 2014). Addition of two types of bacteria to determine the performance of bacteria that play an active role when making change to bioactive compounds, and to know the performance of those local bacteria when added to bacteria to cabbage that will be used by the lactic acid bacteria for their growth. Addition of a combination of bacteria to determine the acidity in sauerkraut, if the two types of bacteria added will be equally active and work in the fermentation process.

Concerning on the salt concentration in sauerkraut fermentation, consumers tend to prefer lower sodium foods. Moreover, the brine in the fermentation contains very high in nondegradable chloride ions and BOD. The ability to reduce the salt in sauerkraut fermentation would reduce the concentration of sodium chloride in the waste stream and the volume of brine formed (Johanningsmeier et al., 2007). The salt has a function to draw water out of nutrients contained in cabbage that will be used by the substrate for the growth of lactic acid 
bacteria. The addition of $2 \%$ salt can accelerate the fermentation process of sauerkraut but is less effective in inhibiting the growth of pathogenic microorganisms. However, the high salt concentration will kill the lactic acid bacteria. Therefore the addition of lactic acid bacteria culture can reduce the salt addition while the fermentation process still go well and increase bioactive compounds (Xiaozhe et al., 2019). Several researchers reported that starter cultures favored the low salt sauerkraut fermentation (Tolonen et al., 2004; Wiander and Ryhanan, 2005).

On the other hand, Penas et al. (2010) reported that antioxidant activity increase during sauerkraut fermentation, lactic acid bacteria capable to increase the bioactive compounds i.e. phenolic and glucosinolate compounds. Phenolic compounds have the ability to increase antioxidant activity, furthermore can avoid degenerative diseases (Murray, 2009), while sulforaphane is an isothiocyanate derivative that has antiproliferative, anti-inflammatory, antioxidant, and anti -cancer activities. The ability to prevent cancer through DNA protection by modulating enzymes and inhibiting gene mutations (Romeo et al., 2018). Antioxidant activity in sauerkraut can inhibit nitric oxide (NO) a factor that causes inflammation that is one of the responses in immune cells (Penas et al., 2012).

This research aimed to study the effect of starter cultures application of $L$. plantarum and $L$. mesenteroides at lower salt fermentation on the sauerkraut quality.

\section{Materials and methods}

\subsection{Materials}

White cabbage (Brassica olerace L. var) used in this experiment was purchased from the local market. Cultures of L. mesenteroides FNCC 0023 and $L$. plantarum FNCC 0027 were obtained from Food and Nutrition Culture Collection, Gadjah Mada University. The cultures were maintained routinely on a MRSB medium.

\subsection{Starter culture preparation}

The starter cultures of $L$. mesenteroides and $L$. plantarum were prepared according to Penas et al., (2012). A loopful of the culture was inoculated into 7 $\mathrm{mL}$ of MRSB medium and incubated at $37^{\circ} \mathrm{C}$ for $16 \mathrm{hrs}$. The culture suspension was harvested by centrifugation at $6000 \mathrm{rpm}$ for $15 \mathrm{mins}$. The cells were washed with sterile distilled water, then put it into a $100 \mathrm{~mL}$ of sterile distilled water with cell density of $10^{6} \mathrm{CFU} / \mathrm{mL}$.
The fresh cabbage was washed, cut, added with salt at different concentration $(0.5 \%$ or $1 \%)$, inoculated with different starter culture (L. plantarum, L. mesenteroides or the combination) at $20 \%(\mathrm{v} / \mathrm{w})$, then incubated at room temperature $\left(28^{\circ} \mathrm{C}\right)$ for 5 days. Spontaneous fermentation with salt at $2 \%$ was used as a control. The obtained sauerkrauts were subjected to evaluation of the quality i.e. total lactic acid bacteria, $\mathrm{pH}$, total acidity, total phenolic content and DPPH scavenging activity analysis. The sulforaphane content analysis was performed on the selected sauerkraut.

\subsection{Sauerkraut quality evaluation}

\subsubsection{Total lactic acid bacteria}

Total lactic acid bacteria were determined according to Penas et al. (2010). A total of $5 \mathrm{~g}$ of the sample was prepared aseptically to make a sample solution, then diluted with buffer peptone water into serial dilution. The diluted sample suspension was poured on MRS Agar and then incubated at $37^{\circ} \mathrm{C}$ for $48 \mathrm{hrs}$.

\subsubsection{Total acidity and $\mathrm{pH}$}

Total acidity was measured according to Ranggana (1977) by using direct titration with $\mathrm{NaOH}$ solution of $0.1 \mathrm{~N}$ and phenol-phtalein indicator. Total acidity was expressed as percentage of lactic acid. $\mathrm{pH}$ was measured by using $\mathrm{pH}$ meter (Manual $\mathrm{pH}$ meter Micro Bench TI 2100).

\subsubsection{Total phenolic content}

One gram of sample was extracted in $10 \mathrm{~mL}$ of methanol, centrifuged at $6000 \mathrm{rpm}$ for 20 mins. $0.5 \mathrm{~mL}$ of supernatant was put into the test tube, added with 2.5 $\mathrm{mL}$ of $10 \%$ Folin Ciocalteau reagent and $2.5 \mathrm{~mL}$ of $7.5 \%$ $\mathrm{Na}_{2} \mathrm{CO}_{3}$, and incubated at room temperature for $90 \mathrm{mins}$. Absorbance was measured at $750 \mathrm{~nm}$ with spectrophotometer (Yang et al., 2007). Gallic acid was used as a standard. The total phenolic content in sauerkraut was expressed as $\mathrm{mg} \mathrm{GAE/g.}$

\subsubsection{DPPH scavenging activity}

The extract was prepared with the same procedure of the total phenolic content analysis. The supernatant was diluted into 10, 20, 30, 40 and $50 \mathrm{ppm} .4 \mathrm{~mL}$ of sample was added into $1 \mathrm{~mL}$ of $0.2 \mathrm{mM}$ diphenyl-1picrylhydrazyl radical (DPPH). The mixture was incubated in the darkroom for $30 \mathrm{mins}$, then the absorbance was measured at $517 \mathrm{~nm}$ with a spectrophotometer (Molyneux, 2004). The DPPH scavenging activity was expressed as $\mathrm{IC}_{50}$.

\subsubsection{Sulforaphane content analysis}

Sulforaphane was analyzed by using Liquid 
Chromatography-Mass Spectrometry (LC-MS) according to Kim et al. (2017). Sample preparation was conducted according to Liang et al. (2006) with the following procedure: $5 \mathrm{~g}$ of the sample was extracted with methylene chloride, dissolved in acetonitrile and filtered through a $0.22 \mu \mathrm{m}$ membrane. The extract was injected to an HPLC system (Agilent Seris 1200) connected to electrospray ionization (ESI) with API 400 Q TRAP Mass Spectrometry system. The LC operating conditions were reversed-phase C18 column in an oven set at $30^{\circ} \mathrm{C}$, mobile phase of $20 \%$ acetonitrile in water then changed linearly to $60 \%$ acetonitrile with flow rate was $1 \mathrm{~mL} / \mathrm{min}$. The MS operating conditions were as follow: ESI positive ion $([\mathrm{M}+\mathrm{H}]+)$, ion spray voltage $(5.5 \mathrm{kV})$, gas (20 psi), nebulisation gas (50 psi), heater gas (50 psi), high purity nitrogen (N2), heater gas temperature $\left(550^{\circ} \mathrm{C}\right)$, declustering potential $(100 \mathrm{~V})$, entrance potential $(10 \mathrm{~V})$, and spectrum range $(\mathrm{m} / \mathrm{z} 100$ -1000). Then the sulforaphane content calculation was done using a standard sulforaphane curve and expressed as $\mu \mathrm{g} / \mathrm{g}$.

\subsection{Statistical analysis}

The data were analyzed by analysis of variance (ANOVA), followed by the LSD test at $\mathrm{p}<0.05$.

\section{Results and discussion}

Table 1. Total Lactic Acid Bacteria (LAB) total acidity before and after in sauerkraut fermentation at different starter cultures and salt concentrations

\begin{tabular}{lccc}
\hline \multirow{2}{*}{\multicolumn{1}{c}{ Culture }} & \multirow{2}{*}{ Salt $(\%)$} & \multicolumn{2}{c}{ Total of LAB } \\
\cline { 3 - 4 } & & $10^{6}(\mathrm{CFU} / \mathrm{mL})$ & $10^{8}(\mathrm{CFU} / \mathrm{mL})$ \\
\hline L. plantarum & 0.5 & $2.4 \pm 0.11$ & $3.4 \pm 0.06^{\mathrm{d}}$ \\
L. mesenteroides & & $2.7 \pm 0.10$ & $2.4 \pm 0.10^{\mathrm{e}}$ \\
L. plantarum + L. mesenteroides & & $2.3 \pm 0.14$ & $5.5 \pm 0.12^{\mathrm{b}}$ \\
L. plantarum & 1 & $2.5 \pm 0.01$ & $4.6 \pm 0.11^{\mathrm{c}}$ \\
L. mesenteroides & & $2.3 \pm 0.14$ & $3.1 \pm 0.09^{\mathrm{d}}$ \\
L. plantarum + L. mesenteroides & & $2.6 \pm 0.23$ & $6.6 \pm 0.10^{\mathrm{a}}$ \\
Control (Spontaneous fermentation) & 2 & $2.6 \pm 0.23$ & $2.6 \times 10^{7} \pm 0.23$ \\
\hline
\end{tabular}

The values are expressed as a mean \pm SD $(n=3)$, and values in a column with the same letters are not significantly $(\mathrm{P}>0.05)$ different.

Table 2. Total acidity and $\mathrm{pH}$ before and after in sauerkraut fermentation at different starter cultures and salt concentrations

\begin{tabular}{lccccc}
\hline \multirow{2}{*}{ Culture } & \multirow{2}{*}{ Salt (\%) } & \multicolumn{2}{c}{ Total acidity (\%) } & \multicolumn{2}{c}{$\mathrm{pH}$} \\
\cline { 3 - 6 } & & Day 0 & Day 5 & Day 0 & Day 5 \\
\hline L. plantarum & \multirow{2}{*}{0.5} & $0.35 \pm 0.02$ & $1.33 \pm 0.04^{\mathrm{c}}$ & $5.67 \pm 0.03$ & $3.69^{\mathrm{a}} \pm 0.19$ \\
L. mesenteroides & $0.37 \pm 0.03$ & $1.31 \pm 0.01^{\mathrm{c}}$ & $5.75 \pm 0.12$ & $3.79^{\mathrm{a}} \pm 0.20$ \\
L.plantarum + L. mesenteroides & & $0.34 \pm 0.01$ & $2.05 \pm 0.05^{\mathrm{a}}$ & $5.72 \pm 0.05$ & $2.60^{\mathrm{b}} \pm 0.13$ \\
L. plantarum & & $0.37 \pm 0.01$ & $1.60 \pm 0.03^{\mathrm{b}}$ & $5.68 \pm 0.02$ & $3.39^{\mathrm{a}} \pm 0.06$ \\
L. mesenteroides & \multirow{2}{*}{1} & $0.39 \pm 0.01$ & $1.51 \pm 0.03^{\mathrm{bc}}$ & $5.68 \pm 0.02$ & $3.46^{\mathrm{a}} \pm 0.10$ \\
L.plantarum + L. mesenteroides & & $0.38 \pm 0.01$ & $2.11 \pm 0.18^{\mathrm{a}}$ & $5.72 \pm 0.05$ & $2.54^{\mathrm{b}} \pm 0.19$ \\
\hline
\end{tabular}

The values are expressed as a mean $\pm \mathrm{SD}(\mathrm{n}=3)$, and values in a column with the same letters are not significantly $(\mathrm{P}>0.05)$ different. 
maintain a $\mathrm{pH}$ gradient at high organic acid concentration. McDonald et al. (2009) revealed that the growth of $L$. mesenteroides stopped when a $\mathrm{pH}$ of 5.4 to 5.7 was reached, while the growth of $L$. plantarum stopped when $\mathrm{pH}$ of 4.6 to 4.8 was reached. In the sauerkraut fermentation, the initial $\mathrm{pH}$ in a range of 5.67 and 5.75. Consequently, the $\mathrm{pH}$ shift for $L$. mesenteroides growth was lower than that for $L$. plantarum. The results of the analysis of variance showed that the addition of culture and salt treatments gave a significant effect $(\mathrm{P}<0.05)$ on the increasing of total lactic acid bacteria. Fermentation at $1 \%$ salt resulted higher total LAB than that of $0.5 \%$. Salt can pull out the juice containing nutrients in the cabbage. Higher salt concentration, more juice pulled out, consequently more nutrients are available for the LAB growth. However, total LAB in sauerkraut control was lower although the fermentation was carried out at higher salt concentration Table 1. It may be due to the lower LAB loaded at initial fermentation in the control without starter culture. Other researchers also reported that the addition of starter culture can expedite the fermentation process and increase total lactic acid bacteria (Beganovic et al., 2011; Yang et al., 2019).

Addition of starter culture affected significantly on the total acidity and $\mathrm{pH}$ after fermentation at salt $0.5 \%$ and $1.0 \%$. It reflects the $\mathrm{LAB}$ produce organic acid during the fermentation. Those are supported by the data of $\mathrm{pH}$ values, whereby the values at final fermentation were lower than those at the initial. These chemical changes are related to the LAB growth during the fermentation. Total acidity and $\mathrm{pH}$ of the fermentation product at the combination cultures treatment respectively higher and lower than those at single culture treatment. This agrees with several researchers reports that $L$. mesenteroides produce lactic acid and acetic acid, which caused $\mathrm{pH}$ decreasing. L. plantarum and L. brevis continuing the fermentation until the $\mathrm{pH}$ around $3(\mathrm{Lu}$ et al., 2003; Plengvidhya et al., 2007; Swain et al., 2014). The bacteria oxidize ethanol to acetaldehyde to acetic acid (Chu and Chen, 2006).

\subsection{Antioxidant activity and total phenolic contents}

The in vitro DPPH scavenging ability increased after fermentation of the sauerkraut at all the treatments, reflected from the lower values of $\mathrm{IC}_{50}$ at after fermentation than those at before fermentation as presented in Table 3. Lactic acid bacteria are able to activate enzymes that having the function of breaking down the phenolic complex into simple compounds (Tolonen et al., 2004). Invertase, cellulase and amylase are able to break complex bonds between phenolic and other compounds so that increase in total phenolic content during fermentation (Essawet et al., 2015). The antioxidant activities correlate to the total phenolic contents, which naturally present in the cabbage and increased during the fermentation. Other researchers also reported that the increase of total phenol in sauerkraut goes hand in hand with an increase of antioxidant activity (Ciska et al., 2005; Martinez-Villaluenga et al., 2012; Penas et al., 2012). The bioactive compounds are able to convert free radical compounds into more stable compounds by donating hydrogen atoms and their aromatic hydroxyl (OH) groups (Dipti et al., 2003).

Both L. plantarum and L. mesenteroides are able to metabolize phenolic compounds in foods. Surprisingly, the lowest $\mathrm{IC}_{50}$ values, both at salt $0.5 \%$ and $1 \%$, were found at the addition of $L$. mesenteroides culture. The highest increment of total phenolic content occurred in the addition of $L$. mesenteroides culture, consistent with the antioxidant activity.

\subsection{Sulforaphane content}

The sauerkraut with the highest antioxidant activity was subjected to sulforaphane content analysis by using LC-MS. The chromatogram of the sample and standard are shown in Figure 1. Sulforaphane is a glucosinolate derivative compound widely found as biologically active compound in cabbage. Sulforaphane content in the sauerkraut with- and without $L$. mesenteroides culture is presented in Table 4. Sulforaphane content in the sauerkraut with $L$. mesenteroides starter culture was higher than that of the control. This indicates that the addition of $L$. mesenteroides culture can increase myrosinase activity to break down the glucose bonds on glucoraphanin so that sulforaphane compound is active as antioxidants. Moreover, it has antiproliferative, antiinflammatory and anti-cancer activities (Xu et al., 2005; Sayed et al., 2014). Sulforaphane has a role in apoptosis of cell proliferation, cancer evolution and stimulation of tumor necrosis factor (TNF- $\alpha$ ), IL-1, Lipopolysaccharide (LPS) and in oxidative stress (Suganuma et al., 2011; Thakur et al., 2014; Nallasamy et al., 2014; Greaney et al., 2016). Another compound was also detected by the

Table 4. Sulforaphane content in sauerkraut

\begin{tabular}{lc}
\hline \multicolumn{1}{c}{ Product } & Sulforaphane $(\mu \mathrm{g} / \mathrm{g})$ \\
\hline Sauerkraut control (Without culture) & $776.47 \pm 3.21^{\mathrm{a}}$ \\
Sauerkraut & $848.65 \pm 2.14^{\mathrm{b}}$ \\
(L. mesenteroides) & \\
\hline
\end{tabular}

The values are expressed as a mean $\pm \mathrm{SD}(\mathrm{n}=3)$. The different letter in the same column indicate a significant difference between $(\mathrm{p}<0.05)$.

LC-MS with $\mathrm{m} / \mathrm{z}$ value of 105 and Rt 1.58 namely 2phenethyl isothiocyanate antimicrobial compound (Abbaoui et al., 2015). 
Table 3. Total phenolic content and antioxidant activities before and after in sauerkraut fermentation at different starter cultures and salt concentrations

\begin{tabular}{|c|c|c|c|c|c|}
\hline \multirow{2}{*}{ Culture } & \multirow{2}{*}{ Salt $(\%)$} & \multicolumn{2}{|c|}{ Total Phenolic Content (mg GAE/g) } & \multicolumn{2}{|c|}{ Antioxidant Activities, $\mathrm{IC}_{50}(\mathrm{ppm})$} \\
\hline & & Day 0 & Day 5 & Day 0 & Day 5 \\
\hline L. plantarum & & $29.99 \pm 0.01$ & $58.33 \pm 1.46^{\mathrm{c}}$ & $155.55 \pm 0.12$ & $120.07 \pm 3.64^{\mathrm{a}}$ \\
\hline L. mesenteroides & 0.5 & $29.89 \pm 0.03$ & $71.50 \pm 0.20^{\mathrm{a}}$ & $152.45 \pm 0.31$ & $95.55 \pm 2.37^{\mathrm{c}}$ \\
\hline L. plantarum + L. mesenteroides & & $29.99 \pm 0.18$ & $64.10 \pm 0.96^{\mathrm{b}}$ & $150.44 \pm 1.21$ & $99.62 \pm 5.68^{\mathrm{bc}}$ \\
\hline L. plantarum & & $29.00 \pm 1.17$ & $59.80 \pm 0.20^{\mathrm{c}}$ & $150.73 \pm 2.00$ & $110.13 \pm 0.74^{\mathrm{ab}}$ \\
\hline L. mesenteroides & 1 & $29.50 \pm 0.18$ & $72.99 \pm 0.88^{\mathrm{a}}$ & $154.01 \pm 1.67$ & $94.85 \pm 1.66^{\mathrm{c}}$ \\
\hline L. plantarum + L. mesenteroides & & $29.68 \pm 0.13$ & $65.48 \pm 0.69^{\mathrm{b}}$ & $151.52 \pm 1.60$ & $98.84 \pm 1.36^{\mathrm{c}}$ \\
\hline
\end{tabular}

The values are expressed as a mean \pm SD $(n=3)$. The different letter in the same column indicate a significant difference between data on the day 0 and day $5(\mathrm{p}<0.05)$. GAE $=$ Gallic acid equivalent, $\mathrm{IC}_{50}$ (inhibition concentration at $50 \%$ scavenging).
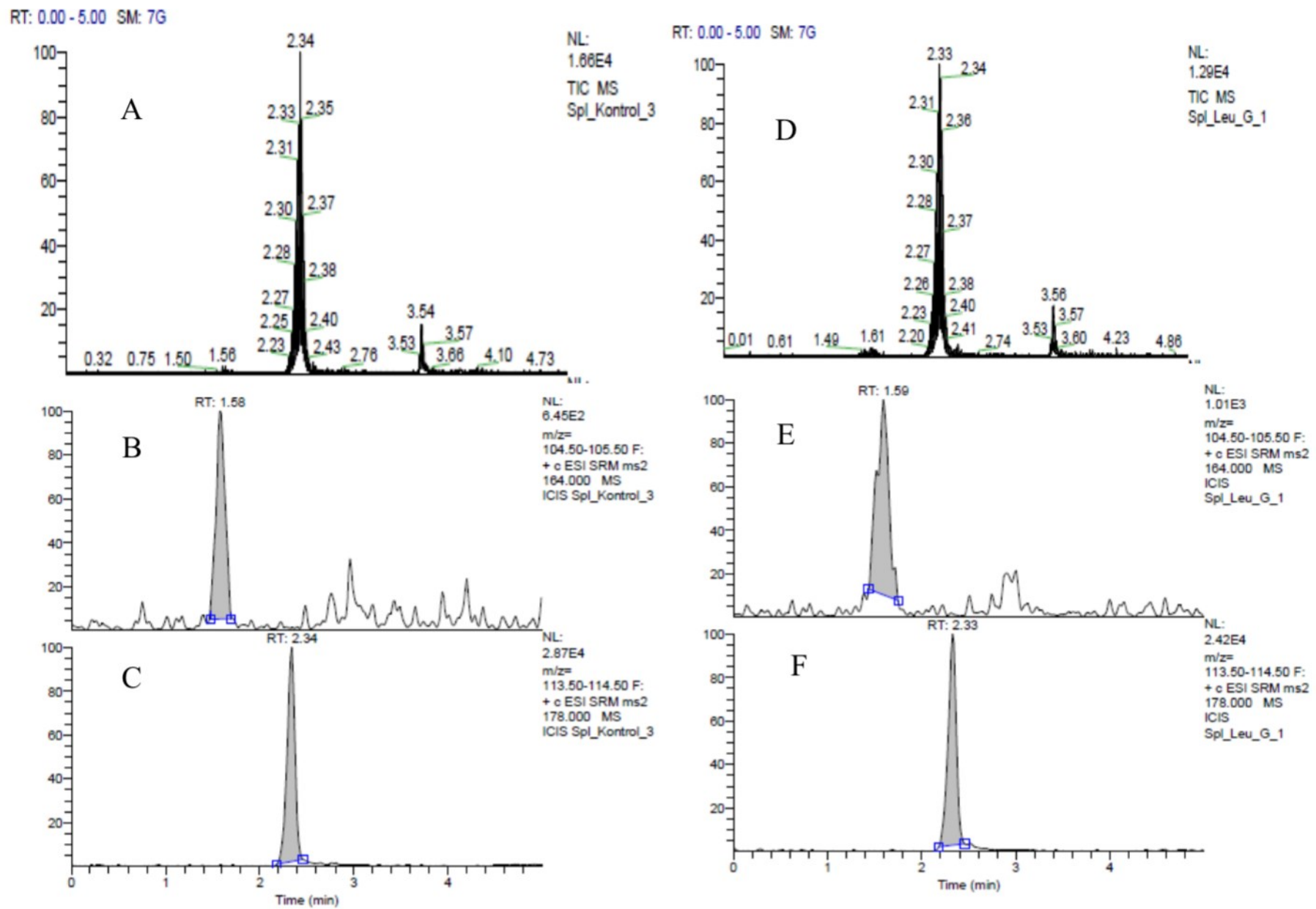

Figure 1. Total ion chromatogram (TIC) of LC-MS analysis of: (A) 2-phenethyl isothyocianate (control); (B) Sulforaphane (control); (C), (D) TIC (sauerkraut + L. mesenteroides); (E) 2-phenethyl isothyocianate (sauerkraut + L. mesenteroides), and (F); Sulforaphane (sauerkraut + L. mesenteroides)

\section{Conclusion}

The starter cultures application of L. plantarum and/ or L. mesenteroides at lower salt fermentation increased total lactic acid bacteria, total acidity and decreased $\mathrm{pH}$. L. mesenteroides resulted in the highest total phenolic content and the lowest $\mathrm{IC}_{50}$ value. Sauerkraut with the addition of $L$. mesenteroides contains sulforaphane higher than that of control.

\section{Conflict of interest}

The authors declare no conflict of interest

\section{Acknowledgments}

This work was financially supported through Professor Research Grant Brawijaya University with grant number 2571/UN10.F10/PN/2019.

\section{References}

Abbaoui, B., Lucas, C.R., Riedl, K.M., Clinton, S.K. and Mortazavi, A. (2015). Cruciferous vegetables, isothiocyanates, and prevention of bladder cancer. Current Pharmacology Reports, 1(4), 272-282. https://doi.org/10.1007/s40495-015-0024-z 
Beganovic, J., Pavune, A.L. Gjuracic, K., Spoljarec, M., Suskovic, J. and Kos, B. (2011). Improved sauerkraut production with probiotic strain Lactobacillus plantarum L4 and Leuconostoc mesenteorides LMG 7954. Journal of Food Science, 76(2), M124-M129. https://doi.org/10.1111/j.17503841.2010.02030.x

Martinez-Villaluenga, C., Penas., E., Sidro, B., Ullate, M., Frias, J. and Vidal-Valverde, C. (2012). White cabbage fermentation improves ascorbigen content, antioxidant and Nitric Oxide production inhibitory activity in LPS-induced macrophages. LWT-Food Science and Technology, 46(1), 77-83. https:// doi.org/10.1016/j.lwt.2011.10.023

Chu, C.S. and Chen, C. (2006). Effect of origin and fermentation time on the antioxidant activity of kombucha. Food Chemistry, 98(3), 502-507. https:// doi.org/10.1016/j.foodchem.2005.05.080

Ciska, E., Magdalena, K. and Agnieszka, K. (2005). Antioxidant activity of extracts of white cabbage and sauerkraut. Polish Journal of Food and Nutrition Sciences, 55(4), 367-373.

Dipti, P., Yogesh, B., Kain, A.K., Pauline, T., Anju, B., Sairam, M., Singh, B., Mongia, S.S., Kumar, G.I. and Selvamurty, W. (2003). Lead induced oxidative stress: beneficial effects of kombucha tea. Biomedical Environment Science, 16(3), 276-282.

Goh, W.N., Rosma, A., Kaur, B., Fazilah, A., Karim, A.A. and Bhat, R. (2012). Fermentation of black tea broth (kombucha): I. Effects of sucrose concentration and fermentation time on the yield of microbial cellulose. International Food Research Journal, 19(1), 109-117.

Greaney, A.J., Maier, N.K., Leppla, S.H. and Moayeri, M. (2016). Sulforaphane inhibits multiple inflammasomes through an Nrf2-independent mechanism. Journal of Leukocyte Biology, 99(1),189 -199. https://doi.org/10.1189/jlb.3A0415-155RR

Johanningsmeier, S., McFeeters, R.F., Fleming, H.F. and Thompson, R.L. (2007). Effects of Leuconostoc mesenteroides starter culture on fermentation of cabbage with reduced salt concentrations. Journal of Food Science, 72(5), M166-172. https:// doi.org/10.1111/j.1750-3841.2007.00372.x

Kim, H.J., Lee, M.J., Jeong, M.H. and Kim, J.E. (2017). Identification and quantification of glucosinolates in kimchi by liquid chromatography-electrospray tandem mass spectrometry. International Journal of Analytical Chemistry, 2017, 1-8. https:// doi.org/10.1155/2017/6753481

Liang, H., Yuan, Q.P, Dong, F.R. and Liu, Y.M. (2006). Determination of sulfurpahane in broccoli and cabbage by high-performance liquid chromatography. Journal of Food Composition and Analysis, 19(5), 473-476. https://doi.org/10.1016/ j.jfca.2005.11.005

Lu, Z., Breidt, F., Plengvidhya, V. and Fleming, H.P. (2003). Bacteriophage ecology in commercial sauerkraut fermentations. Applied and Environmental Microbiology, 69, 3192-3202. https:// doi.org/10.1128/AEM.69.6.3192-3202.2003

McDonald, L.C., Fleming, H.P. and Hassan, H.M. (2009). Acid Tolerance of Leuconostoc mesenteroides and Lactobacillus plantarum. Applied Environmental Microbiology, 56(7), 2120-2124. https://doi.org/10.1128/AEM.56.7.2120-2124.1990

Molyneux, P. (2004). The use of the stable free radical diphenyl picryl hydrazyl (DPPH) for estimating antioxidant activity. Songklanakarin Journal of Science and Technology, 26(2), 211-219.

Murray, R.K., Granner, D.K. and Rodwell, V.W. (2009). Biokimia. Harper. $27^{\text {th }}$ ed. Jakarta: Buku Kedokteran EGC.

Nallasamy, P., Si, H., Babu, P.V., Pan, D., Fu, Y., Brooke, E.A., Shah, H., Zhen, W., Zhu, H., Liu, D., Li, Y. and Jia, Z. (2014). Sulforaphane reduces vascular inflammation in mice and prevents TNF-ainduced monocyte adhesion to primary endothelial cells through interfering with the NF-jB pathway. The Nutritional Biochemistry, 25(8), 824-833. https://doi.org/10.1016/j.jnutbio.2014.03.011

Penas, E., Martinez-Villaluenga, C., Frias, J., SanchezMrtinez, M.J., Perez-Corona, T.P., Madrid, Y., Camara, C. and Vidal-Valverde, C. (2012). Se improves indoleglucosinolate hydrolysis product content, Se-methylselenocysteine content, antioxidant capacity and potential anti-inflammatory properties of sauerkraut. Food Chemistry, 132(2), 907-914. https://doi.org/10.1016/ j.foodchem.2011.11.064

Penas, E., Frias, J., Sidro, B. and Vidal-Valvede, C. (2010). Chemical evaluation and sensory quality of sauerkraut obtained fermentations at different $\mathrm{NaCl}$ levels from Brassica oleracea Var. capitata $\mathrm{Cv}$. Bronco grown in eastern Spain. Effect of storage. Agricultural and Food Chemistry, 58, 3549-3557. https://doi.org/10.1021/jf903739a

Plengvidhya, V., Breidt, F.Jr., Lu, Z. and Fleming, H.P. (2007). DNA fingerprinting of lactic acid bacteria in sauerkraut fermentations. Applied and Environmental Microbiology, 73, 7697-7702. https:// doi.org/10.1128/AEM.01342-07

Ranggana, S. (1977). Manual of Analysis of Fruit and Vegetable Products. New Delhi, India: McGraw Hill 
Publishing Co.

Romeo, L., Lori, R., Rollin, P., Bramanti, P. and Mazzon, E. (2018). Isothiocyanates: an overview of their antimicrobial activity against human infections. Molecules, 23(3), 624. https://doi.org/10.3390/ molecules 23030624

Sayed, R.H., Khalil, W.K.B., Salem, H.A., Kenawy, S.A. and El-Sayeh, B.M. (2014). Sulforaphane increases the survival rate in rats with fulminant hepatic failure induced by d-galactosamine and lipopolysaccharide. Nutrition Research, 34(11), 982-989. https:// doi.org/10.1016/j.nutres.2014.10.003

Suganuma, H., Fahey, J.W., Bryan, K.E., Healy, Z.R. and Talalay, P. (2011). Stimulation of phagocytosis by sulforaphane. Biochemical and Biophysical Research Communications, 405(1), 146-151. https:// doi.org/10.1016/j.bbrc.2011.01.025

Swain, M.R., Anandharaj, M., Ray, R.C. and Parveen Rani, R. (2014). Fermented fruits and vegetables of Asia: a potential source of probiotics. Biotechnology Research International, 2014, 1-19. https:// doi.org/10.1155/2014/250424

Tolonen, M., Rajaniemi, S., Pihlava., J.M., Korhonen, H. and Ryhanen, E.L. (2004). Formation of nisin, plant derived biomolecules and antimicrobial activity in starter culture fermentations of sauerkraut. Food Microbiology, 21(2), 391-395. https:// doi.org/10.1016/S0740-0020(03)00058-3

Thakur, V.S., Deb, G., Babcook, M.A. and Gupta, S. (2014). Plant phytochemicals as epigenetic modulators: role in cancer chemoprevention. The AAPS Journal, 16(1), 151-163. https:// doi.org/10.1208/s12248-013-9548-5

Xiaozhe. Y., Wenzhong. H., Aili. J., Zhilong. X., Yaru. J., Yuge G., Sarengaowa., Xiangyan. Y. (2019). Effect of salt concentration on quality of northeast sauerkraut fermented by Leuconostoc mesenteroides and Lactobacillus plantarum salt effect on northeast sauerkraut fermentation. Food Bioscience, 30, 1-8. https://doi.org/10.1016/j.fbio.2019.100421

$\mathrm{Xu}, \mathrm{C}$, Shen, G., Chen, C., Gelinas, C. and Kong, A.T.

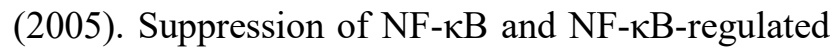
gene expression by sulforaphane and PEITC through $\mathrm{I} \kappa \mathrm{B} \alpha$, IKK pathway in human prostate cancer PC-3 cells. Oncogene, 24, 4486-4495. https:// doi.org/10.1038/sj.onc. 1208656

Yang, J., Paulino, R., Janke-Stedronsky, S. and Abawi, F. (2007). Free radical scavenging activity and total phenol of noni (Moriadaeitrifolia L.) juice and powder in processing and storage. Food Chemistry, 102(1), 302-308. https://doi.org/10.1016/ j.foodchem.2006.05.020
Yang, X., Hu, W., Jiang, A., Xiu, Z., Ji, Y., Guan, Y., Sarenggaowa and Yang, X. (2019). Effect of salt concentration on quality of Chinese northeast sauerkraut fermented by Leuconostoc mesenteroides and Lactobacillus plantarum. Food Bioscience 30, 100421. https://doi.org/10.1016/j.fbio.2019.100421 